\title{
Residual stresses in Inconel 718 engine disks
}

\author{
Yoann Dahan $^{1, a}$, Sebastien Nouveau ${ }^{2}$, Eric Georges ${ }^{3}$, and Benjamin Flageolet ${ }^{4}$ \\ ${ }^{1}$ R\&D Department, Aubert\&Duval, 75 Boulevard de la libération, BP. 173, 09102 Pamiers Cedex, France \\ ${ }^{2}$ R\&D Department, Aubert\&Duval, Advanced Forming Research Centre, University of Strathclyde, 85 Inchinnan Drive, \\ Inchinnan, Renfrewshire, PA4 9LJ Scotland, UK \\ ${ }^{3}$ R\&D Department, Aubert\&Duval, BP. 1, 63770 Les Ancizes, France \\ ${ }^{4}$ Production Engineering Department, 75 Boulevard de la libération, BP. 173, 09102 Pamiers Cedex, France
}

\begin{abstract}
Aubert\&Duval has developed a methodology to establish a residual stress model for Inconel 718 engine discs. To validate the thermal, mechanical and metallurgical parts of the model, trials on lab specimens with specific geometry were carried out. These trials allow a better understanding of the residual stress distribution and evolution during different processes (quenching, ageing, machining). A comparison between experimental and numerical results reveals the residual stresses model accuracy. Aubert\&Duval has also developed a mechanical properties prediction model. Coupled with the residual stress prediction model, Aubert\&Duval can now propose improvements to the process of manufacturing in Inconel 718 engine disks. This model enables Aubert\&Duval customers and subcontractors to anticipate distortions issues during machining. It could also be usedt to optimise the engine disk life.
\end{abstract}

\section{Introduction}

Aubert\&Duval produces Inconel 718 disks for aerospace engines. The specifications of its customers define targets for mechanical properties (creep, tensile or fatigue). To achieve these challenging requirements, Aubert\&Duval applies specific heat treatments. In the case of engine disks made in Inconel 718, its heat treatment can consist of solutioning at $980^{\circ} \mathrm{C}$ for 1 hour followed by water quenching and a double ageing at $720^{\circ} \mathrm{C}$ and $620^{\circ} \mathrm{C}$ for 8 hours respectively (Fig. 1).

While these heat treatments produce the required mechanical properties, high levels of residual stresses are generated when quenching is necessary. Usually, after quenching of a superalloy part, the skin of the part is in a compressive state balanced by the core in a tensile state. The magnitude and the distribution of residual stresses vary during the production steps (ageing, machining ...etc.), which follow the quenching.

Three serious consequences of residual stresses have been identified:

- cracking during heat treatment detected by ultrasonic or penetrant testing inspection,

- distortions during machining,

- influence fatigue life of the engine disks [1].

Residual stresses are a key point for Aubert\&Duval and its customers. Therefore, Aubert\&Duval R\&D department has developed a model for residual stress prediction.

\footnotetext{
${ }^{a}$ Corresponding author: yoann . dahan@eramet-aubertduval . com
}

In this paper, the methodology for residual stress investigation on Inconel 718 disks is presented. It mainly deals with the validation of the residual stress model using a lab specimen. Metallurgical, mechanical properties and residual stress models are presented, coupled and applied to an Inconel 718 pancake representative of engine disks.

\section{Experimental trials}

\subsection{Thermal, mechanical and metallurgical models}

A residual stress model has to integrate thermal, mechanical and metallurgical models which play important roles in the generation and evolution of residual stresses. Each model has a strong interaction with others (Fig. 2).

The thermal conditions during heat treatment and notably during quenching are parameters of first order. For vapourisable media like water, quenching trials with thermocouples are necessary due to the complexity of the liquid flow and phase transformation [3]. Nowadays, these data are completed by evident progress made in Computational Fluid Dynamics (CFD). In the case of a disk cooled by blown air, the software THOST $^{\circledR}$ codeveloped by Aubert\&Duval can be used to study the air flow (Fig. 3).

A constitutive law specifically developed for residual stresses is required. This step always starts with rheological tests required for different temperatures, strain rates and cooling rates. The model to be fitted can be quite simple (elasto-plastic formulation) [4,5] or much more sophisticated (kinematic hardening law) [6]. According to

This is an Open Access article distributed under the terms of the Creative Commons Attribution License 4.0, which permits unrestricted use, distribution, and reproduction in any medium, provided the original work is properly cited. 


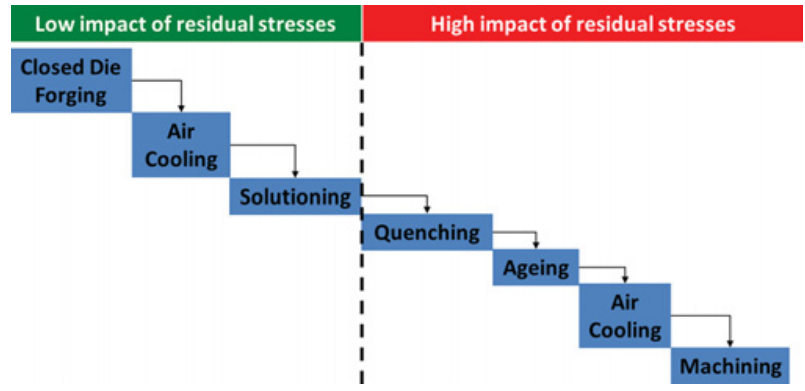

Figure 1. The manufacturing steps of solutioned and quenched engine disks.

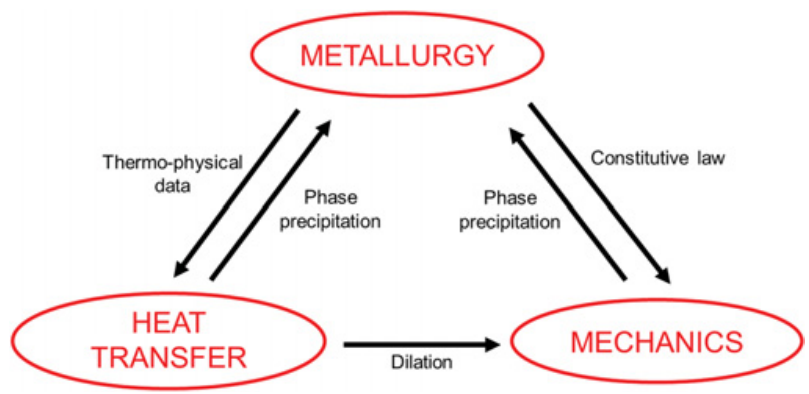

Figure 2. Areas interactions during heat treatment [2].

the uncertainty of the current residual stress measurement methods, an elasto-plastic formulation is found sufficient for accurate residual stress prediction.

An Inconel 718 microstructure evolution (grain size, $\gamma^{\prime \prime}$ precipitation) model can contribute to modify the constitutive law and dilatometry. Nevertheless, phase precipitation and grain size evolution are neglected during the water quenching. Once the thermal, mechanical and metallurgical models are fitted, the overall model can be validated with a lab specimen. Material from several Inconel 718 billets with 6 to 10 ASTM grain size has been evaluated for statistical significance. The R\&D Department of Aubert\&Duval developed different lab geometries to investigate residual stresses and to validate the model parameters. In this paper, only two geometries are presented (Fig. 4). For residual stress measurements, a simple block $(200 \times 90 \times 30 \mathrm{~mm})$ partially quenched by water is sufficient to generate significant residual stresses [7]. For distortion measurements, a specimen with a large thickness variation is preferred. In this case, a shell-shaped geometry $(\Phi 260 \mathrm{~mm})$ is tested. Quenching trials are carried out on each geometry. One specimen is instrumented by several thermocouples to validate the heat exchange coefficients determined previously.

\subsection{Trials on Inconel 718 block specimen}

The partially quenching trials of a block present several advantages. The geometry shape is simple and so easy to machine. For an optimised water level, the residual stress distribution is quite homogenous and presents tensile residual stresses on the specimen surface (Fig. 5).

Residual stresses measurements are made at the centre of the block by centre hole drilling. This method is not extremely accurate $( \pm 100 \mathrm{MPa})$. This is why, in some cases, residual stresses have also been measured

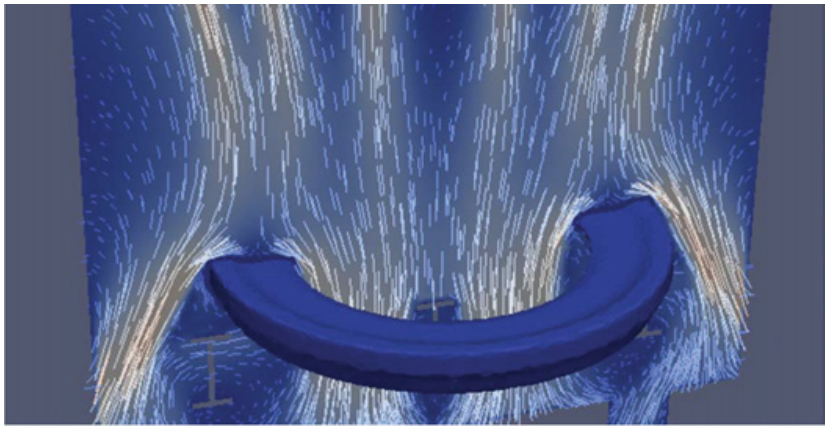

Figure 3. Thost ${ }^{\circledR}$ numerical simulation of the air flow during a disk cooling.
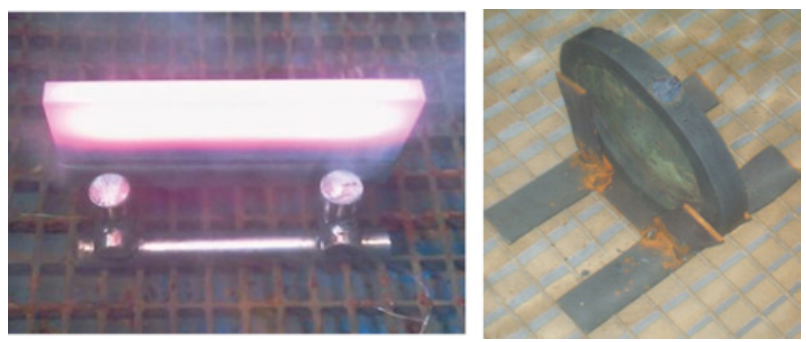

Figure 4. Partially quenched block (left) and quenched shellshape (right) trials [8-10].

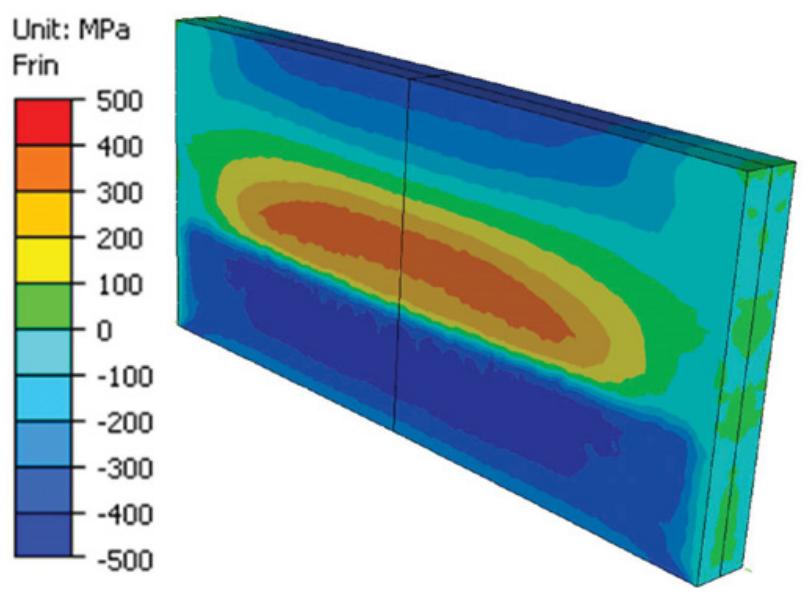

Figure 5. Longitudinal residual stress distribution on a partially quenched block [8].

by X-ray diffraction for which the accuracy can reach $\pm 50 \mathrm{MPa}$. The comparison is very interesting since the different measurement methods quickly converge towards a common value close to the numerical simulation (Fig. 6). Both methods confirm the tensile residual stresses at the centre of the specimen surface.

Several partially quenched trials were carried out. Few blocks were treated at supersolvus conditions to modify the grain size. After quenching, the grain size and the residual stresses were measured at the centre of the block. These measurements show a correlation between the grain size and the von Mises stresses (Fig. 7). This relationship fits well with a Hall and Petch law.

These trials follow the evolution of residual stresses during ageing. Seven specimens were quenched followed 


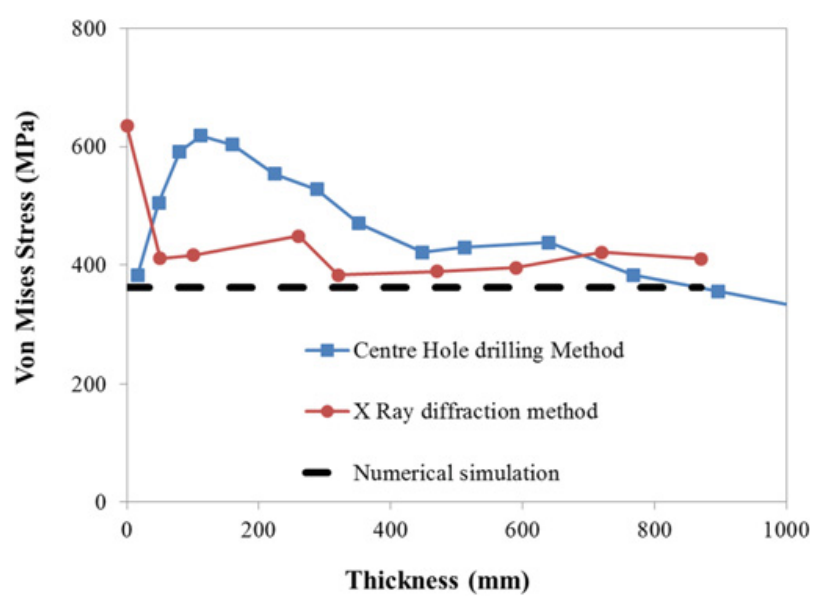

Figure 6. Comparison between centre hole drilling and $\mathrm{X}$ ray diffraction methods [9].

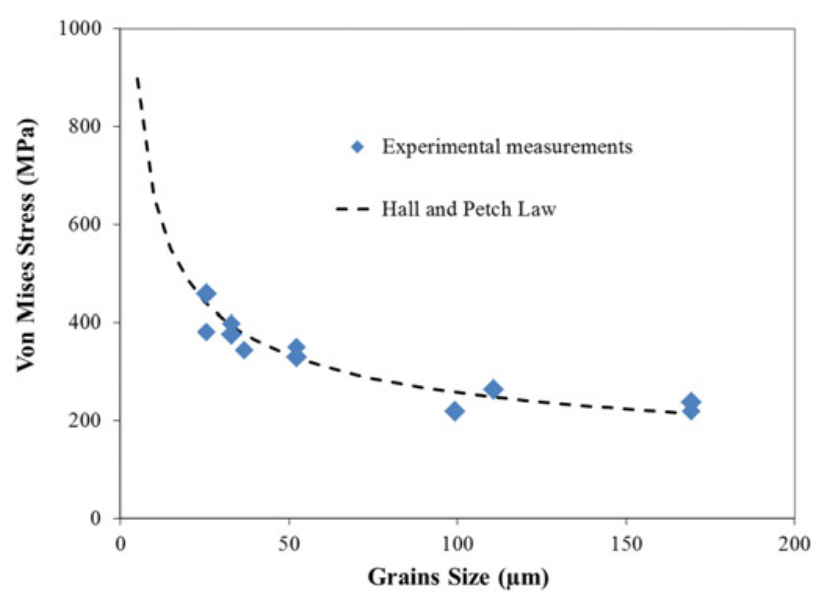

Figure 7. Measured Von Mises residual stress as a function of grains size [10].

by ageing interrupted at various soaking times. The residual stress measurements were carried out on these specimens. The evolution of residual stresses during double ageing is presented in Fig. 8. It appears that the main evolution happens during the first hour of the ageing. This can be explained by the residual stresses relaxation induced at $720^{\circ} \mathrm{C}$. After this soaking time, the residual stress values seem not to change significantly. The precipitation of the $\gamma$ " phase in the matrix of Inconel 718 during ageing contributes to the development of the required tensile properties. If the yield strength increases quickly during the double ageing, the residual stress magnitude reached after 1 hour remains stable.

\subsection{Trials on Inconel 718 shell shape specimen}

The advantage of the shell-shaped specimen is the significant level of distortion obtained after quenching which is measured by a 3D scan. Hence, the residual stresses are estimated indirectly via the distortion measurement, which generates less uncertainty. The 3D scan measurement allows one to analyse the axisymmetry of the distortion and to compare it with the numerical simulation (Fig. 9).

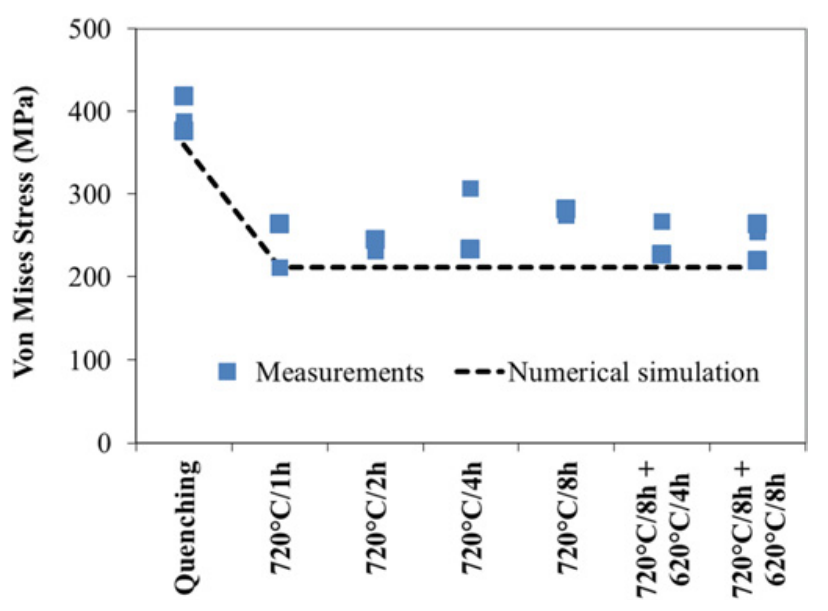

Figure 8. Evolution of residual stresses during ageing [10].

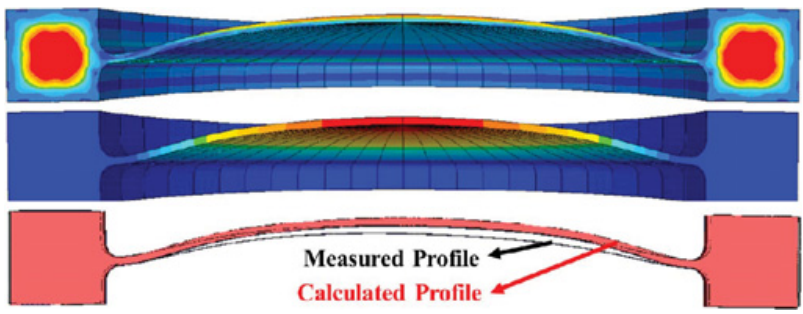

Figure 9. Residual stress distribution (top: Min $-500 \mathrm{MPa}$, Max $500 \mathrm{MPa}$ ) and distortions (bottom: Min $0 \mathrm{~mm}$, Max $13 \mathrm{~mm}$ ) obtained on shell shape specimen [10].

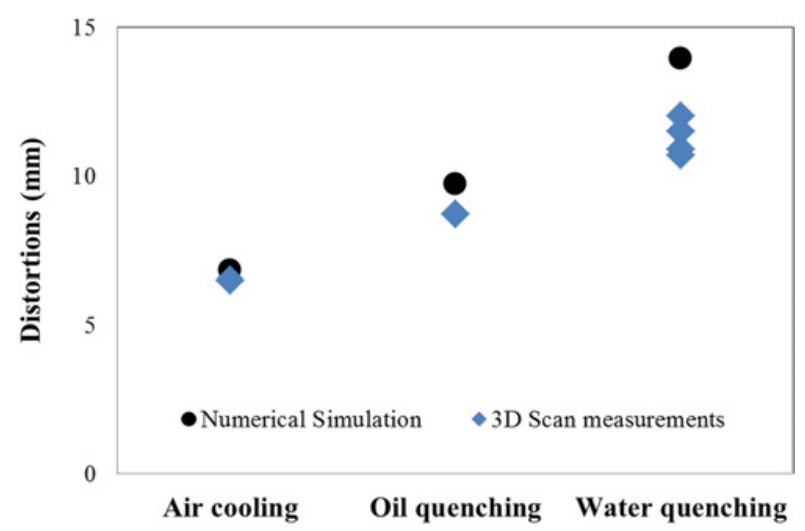

Figure 10. Evolution of distortion of the shell specimen during ageing [9].

Several shell shape specimens were quenched in various conditions. Repeatability tests were carried out and confirm a good reproducility of the trials $( \pm 1 \mathrm{~mm}$ on the level of distortion). As a function of the media, the distortion level of the specimen centre varies significantly from $6 \mathrm{~mm}$ for an air cooled specimen to $12 \mathrm{~mm}$ for a water quenched specimen (Fig. 10). Few shell shape specimens were quenched in a different position (horizontal or vertical) in the water tank. The influence of the specimen orientation is not significant on the distortion level. In the case of water quenching trials, the numerical simulation overestimates the distortion level of $3 \mathrm{~mm}$. This difference shows that further work is required to improve the residual stress model. 

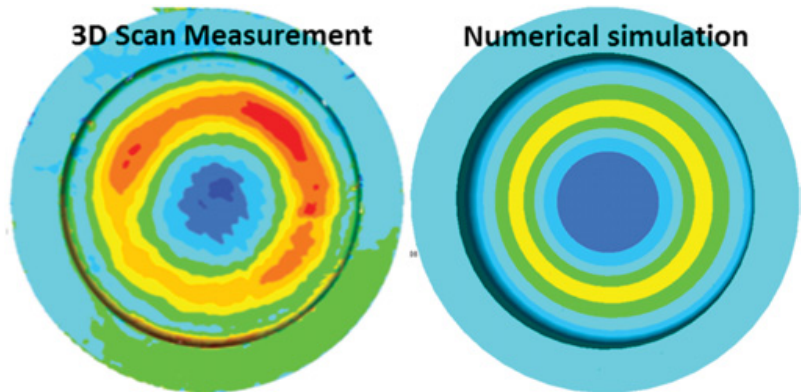

$\begin{array}{llllll}0,6 & 0,5 & 0,4 & 0,3 & 0,2 & 0,1\end{array}$

$\begin{array}{lllll}0 & -0,1 & -0,2 & -0,3 & -0,4\end{array}$

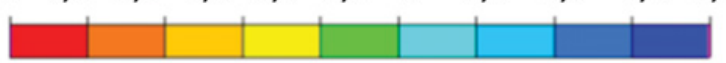

Figure 11. Evolution of distortion during ageing (upper view of the shell-shape specimen) [9].

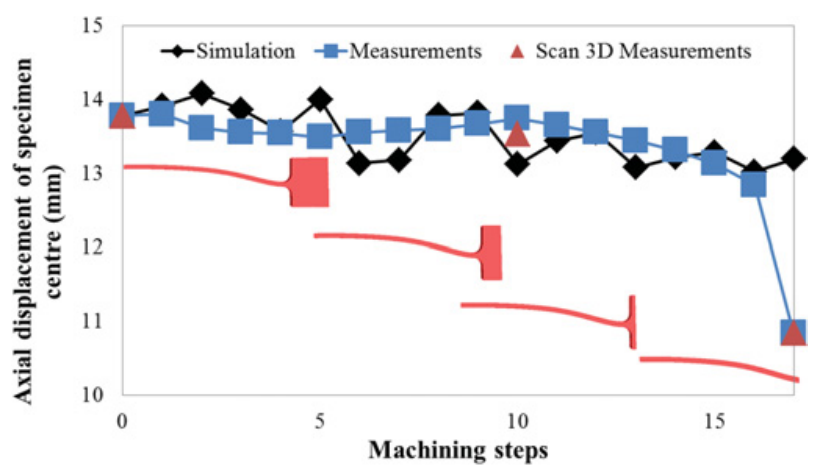

Figure 12. Distortion of the shell specimen during machining [9].

Regarding the shell specimen, an interesting evolution of distortion is observed during the ageing. The centre distortion decreases whereas the mid-radius displacement increases. This evolution is well predicted by numerical simulation (Fig. 11).

The developed model is also appropriate for machining. Different machining steps were tested depending on geometry specimen and residual stress magnitude and distribution. These trials have two purposes: the first is to observe residual stress relaxations. For instance, if all compressive zones are removed by machining, the remaining part of the material, initially in a tensile state, is instantaneously relaxed. Nevertheless, residual stress is still present due to plastic deformation generated during heat treatment. A second purpose of the machining trials is to observe significant distortion. Depending on the specimen geometry and the machining conditions, the distortion can be generated by the machining itself instead of residual stress relaxation.

In the case of the shell-shape specimen, the outer diameter is machined step by step by $2 \mathrm{~mm}$ material removal. The measurements are carried out on the centre of the specimen to evaluate the axial displacement during the machining steps. Figure 12 shows the evolution of the centre specimen during the machining steps. The major displacement occurs during the last steps. The numerical simulation reproduced accurately the evolution of residual stress during machining except for the last step.

The laboratory tests allow validation of the developed model. The magnitude of residual stress and the distortion

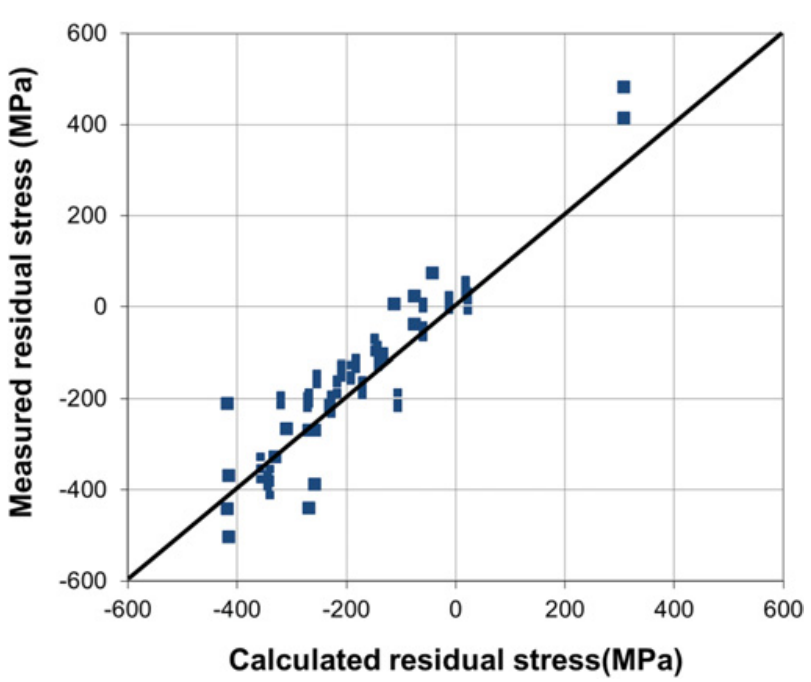

Figure 13. Comparison between experimental measurements and numerical results of residual stress in several disks [8].

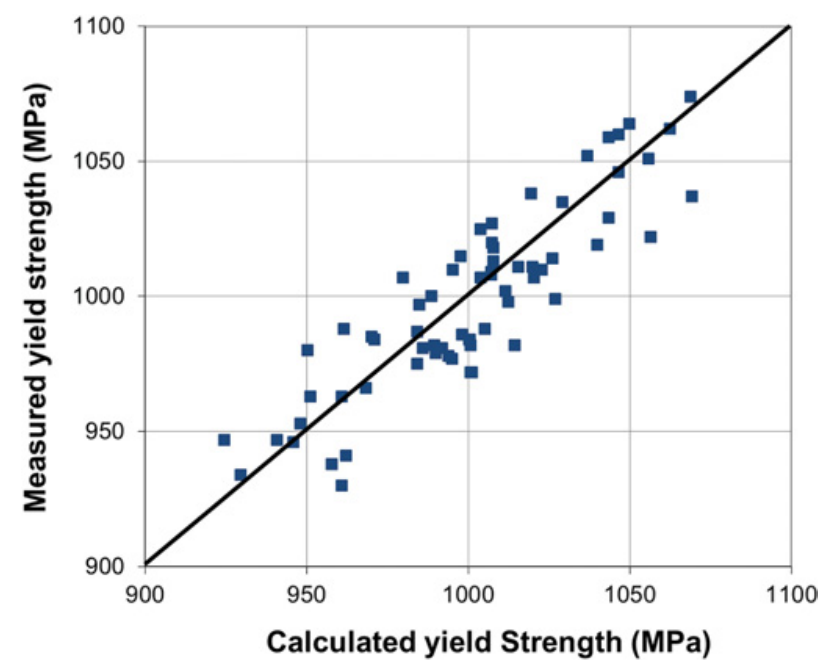

Figure 14. Comparison between experimental measurements and numerical results of $650{ }^{\circ} \mathrm{C}$ yield strength from several disks [16].

seem to be correctly predicted by the model. The next step consists in applying the model to industrial parts to validate it and to link it to two other models developed by Aubert\&Duval: mechanical properties model and microstructure model.

\section{Application on industrial parts}

Once this model had been developed and tested on several lab specimens, it was tested on engine disks on which residual stresses measurements are frequently carried out by the centre hole drilling method. These measurements were planned after ageing and the ultrasonic shape machining. To carry out a comparison between experimental measurements and numerical results, it is important to simulate all the process from solutioning to the ultra-sonic shape machining. The developed model shows a good accuracy, although the residual stress magnitude can be overestimated or underestimate by $100 \mathrm{MPa}$ in some cases (Fig. 13). 


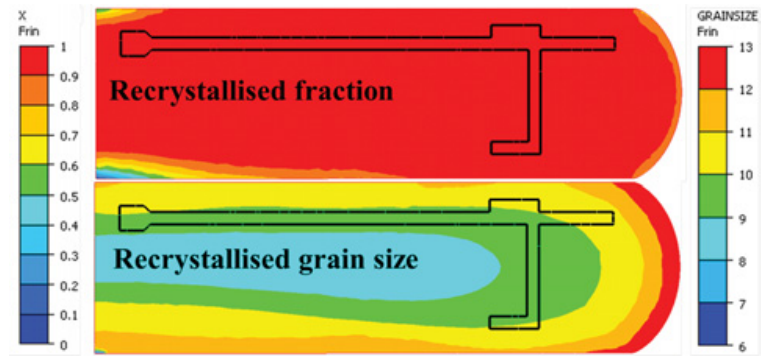

Figure 15. Industrial part presented with microstructure prediction model.
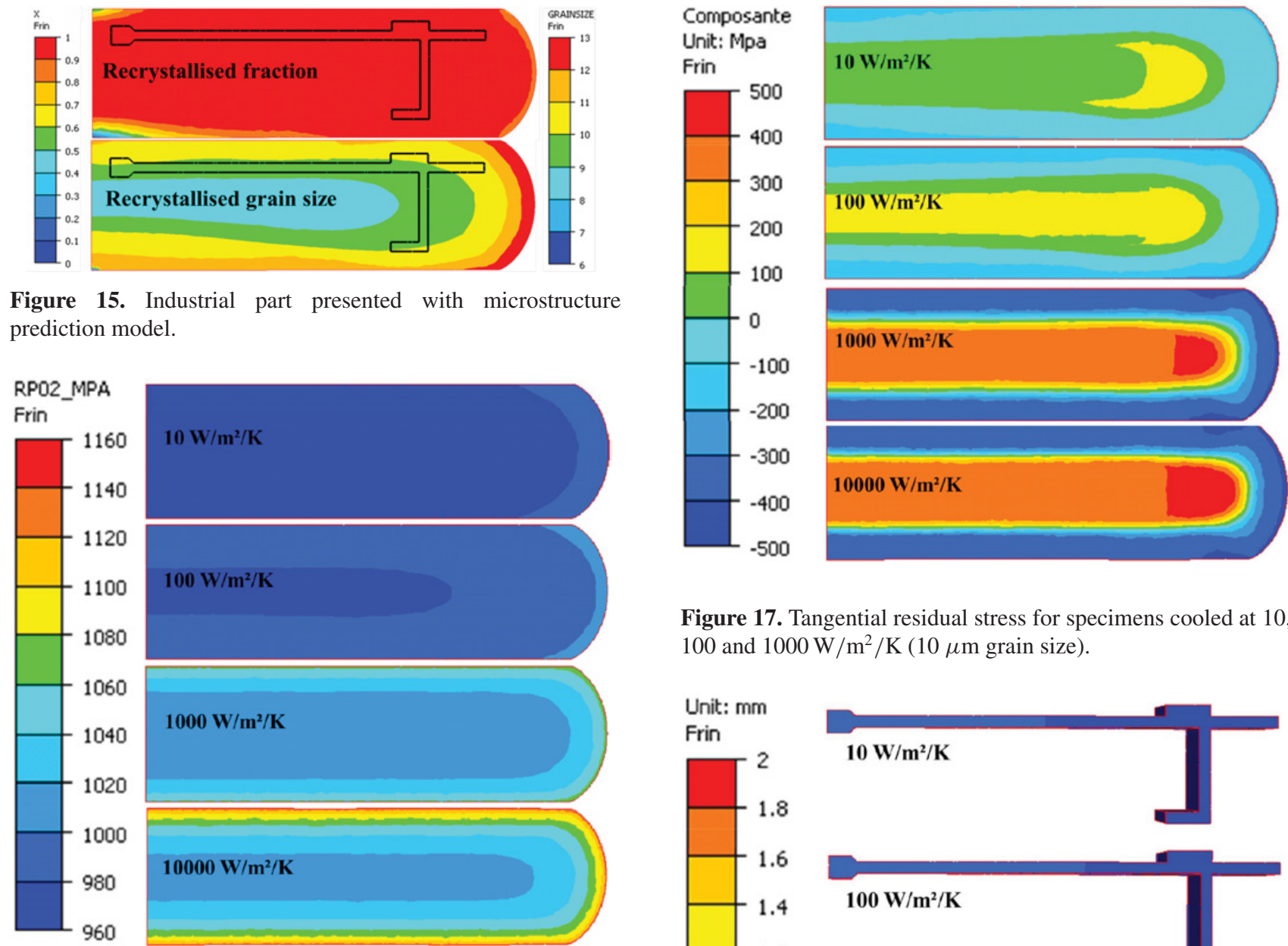

Figure 17. Tangential residual stress for specimens cooled at 10 , 100 and $1000 \mathrm{~W} / \mathrm{m}^{2} / \mathrm{K}(10 \mu \mathrm{m}$ grain size $)$.
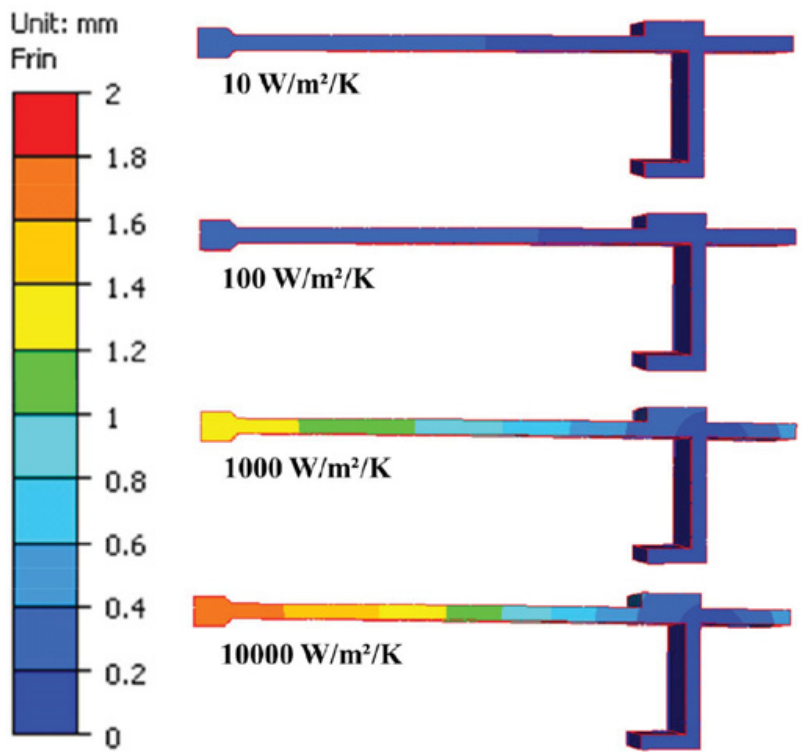

Figure 18. Machining distortion for specimens cooled at 10, 100 and $1000 \mathrm{~W} / \mathrm{m}^{2} / \mathrm{K}(10 \mu \mathrm{m}$ grain size $)$. of the yield strength calculation is $\pm 30 \mathrm{MPa}$ (Fig. 14).

For confidentiality reasons, Aubert\&Duval cannot present examples of residual stress distributions in black forging shapes. As a result, this methodology is applied to an Inconel 718 pancake (weight: 90kg, diameter: $470 \mathrm{~mm}$, height: $70 \mathrm{~mm}$ ), which is relatively representative of forging disks. The prediction model gives accurate estimation of recrystallised fraction and grain size distribution (Fig. 15). To carry out the clearest correlation between yield strength and residual stress, the grain size of the pancake is assumed to be homogenous and equal to 10 $\mu \mathrm{m}$.

Using both mechanical properties and residual stress models, one can estimate the advantages and the drawbacks of different cooling methods (from air cooling to water quenching). This tool allows Aubert\&Duval to propose an adapted solution to reach the expected mechanical properties (according to specification requirements) and to reduce residual stresses. In this paper, the influence of the heat exchange coefficients can be analysed from 10 to $10000 \mathrm{~W} / \mathrm{m}^{2} / \mathrm{K}$. The lowest heat exchange value can correspond to a calm air cooling whereas the highest value can be easily reached during the boiling step of water quenching. Experimentally, the heat exchange coefficient depends also on the specimen position in the media tank and surface orientation. Figures 16, 17 and 18 show the key role of the heat exchange coefficient on yield strength, tangential residual stress and distortion during machining.

There is a clear correlation between cooling rate, yield strength, between residual stress and machining distortion. This analysis allows one to show that if 


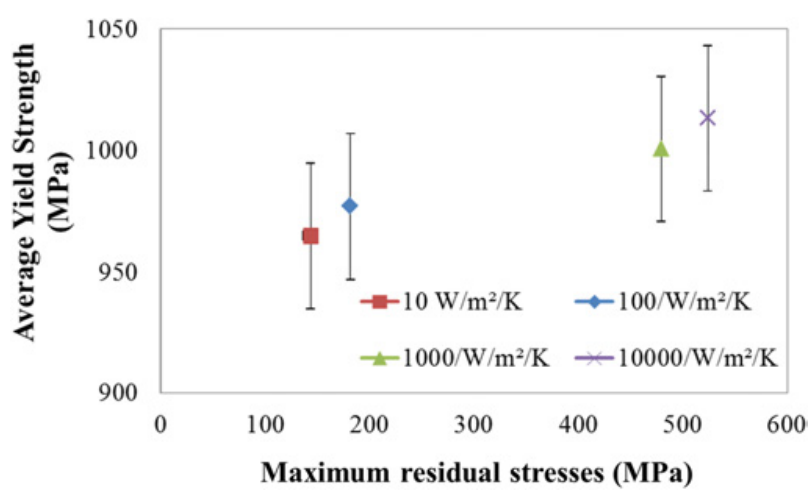

Figure 19. Average $650^{\circ} \mathrm{C}$ yield strength versus the maximum residual stress on the pancake.

the exchange coefficient improves significantly the yield strength, this generates important residual stress. This correlation is presented in Fig. 19. For instance, a cooling rate of $1000 \mathrm{~W} / \mathrm{m}^{2} / \mathrm{K}$ improves the yield strength $(+30$ $\mathrm{MPa}$ ) compared to $100 \mathrm{~W} / \mathrm{m}^{2} / \mathrm{K}$, but generates significant residual stress $(+470 \mathrm{MPa})$ and so potential distortion issue during machining.

\section{Conclusion}

Aubert\&Duval has established a methodology to develop and validate a model for predicting residual stresses in Inconel 718 engine disks. It is based on a combination of thermal, mechanical and metallurgical investigations.

To develop this methodology, Aubert\&Duval has used lab specimens with two complementary geometries. A block which is partially quenched produces:

- residual stress measurements in tensile zones,

- comparisons between X-ray diffraction and centre hole drilling measurements of residual stress,

- a correlation between grain size and residual stresses,

- an evolution of residual stress during ageing.

The shell shape specimen gives complementary results:

- significant distortion during quenching,

- an influence of the cooling media on distortion,

- the distortion evolution during ageing,

- the distortion evolution during machining,

- an accurate comparison with numerical simulation.
Applying this model on engine disks gives accurate residual stress predictions $( \pm 100 \mathrm{MPa})$. Coupling with a precise mechanical properties prediction model $( \pm 30 \mathrm{MPa})$, Aubert\&Duval can now propose improvements to the manufacture of Inconel 718 engine disks. The application of the model to an Inconel 718 pancake has established a correlation between yield strength and residual stress. To reach a $30 \mathrm{MPa}$ improvement in yield strength, an oil or water quenching can be required but generates high levels of residual stress and potential distortion during machining.

To complete the validation on disks, more thermal data and machining distortion measurements are required.

\section{References}

[1] G. Shen, N.Cooper, N. Ottow, R. Goetz, J. Matlik, Superalloys 2012, 130 (2012)

[2] T. Inoue, D.Y. Ju, K. Arimoto, First International conference on Quenching and Control distortion, (1992)

[3] J. Gilles, Etude expérimentale des aspects thermiques liés à une opération de trempe, Thesis, 163 pages (2004)

[4] M.A. Rist, S. Tin, B.A. Roder, J.A. James, M.R. Daymond, Met. Trans, 37A, 459 (2006)

[5] D. Dye, K.T. Conlon, R.C. Reed, Met. Trans. A, 35A, 1703 (2004)

[6] J. Lemaitre, J.L. Chaboche, Mécanique des matériaux solides, Dunod, (1987)

[7] A. Mirzaee-Sisan, D.J. Smith, C.E. Truman, J. St. Ana. Eng. Des., 42,79 (2007)

[8] S. Forget, internal report, 2010

[9] L. Hadji, internal report, 2013

[10] C. Miret, internal report, 2012

[11] S. Coste, Détermination des lois d'évolution microstructurale de l'alliage 718 lors du matriçage. Thesis, 126 pages (2003)

[12] J.P. Thomas, Etude expérimentale et modélisation de l'évolution microstructurale du superalliage 718 en déformation à chaud. Thesis, 186 pages (2005)

[13] E. Georges, internal report, 2007

[14] E. Fourmentin, internal report, 2012

[15] L. Carroz, internal report, 2012

[16] B. Flageolet, internal report, 2012 